\title{
Physician Understanding of Patient Health Beliefs
}

To the Editors:- Street and Haidet appropriately position physician understanding of patient health beliefs as a key feature of patient-centered care (How well do doctors know their patients? Factors affecting physician understanding of patients' health beliefs). ${ }^{1}$ They make a compelling argument for the value of shared understanding, and provide evidence that consonance regarding health beliefs is more likely to be achieved if patients ask questions, express concerns, and offer opinions about their health during a medical encounter.

Of course, health beliefs are just one of the many domains for which shared understanding is critical. At least as fundamental as patients' beliefs about a health problem are their beliefs about health per se. For instance, physicians cannot be expected to successfully counsel patients for better health unless they understand how their patients think about health. In national surveys, we elucidated four distinct and robust conceptions of health in America: capacity (health is an enabling factor); control (health is the result of an individual's behaviors); physical (health is completely physical, focused on the body and biomedical criteria); psychosocial (health is a mix of mental, emotional, social, and spiritual factors). ${ }^{2}$ The

Published online March 31, 2011 importance of assessing and addressing how people define health was reinforced by the finding that $30 \%$ of the overall survey sample did not view health as physical, suggesting that shared understanding about "health" is another important marker of truly patient-centered care.

Gregory Makoul, PhD, Saint Francis Hospital and Medical Center, 114 Woodland Street, Hartford, CT 06105, USA (e-mail:gmakoul@stfranciscare.org).

\section{REFERENCES}

1. Street RL, Haidet P. How well do doctors know their patients? Factors affecting physician understanding of patients' health beliefs. J Gen Intern Med. 2011;26:21-7.

2. Makoul G, Clayman ML, Lynch EB, Thompson JA. Four concepts of health in America: Results of national surveys. $J$ of Health Commun. 2009; 14:3-14

$\mathrm{J}$ Gen Intern Med 26(6):574

DOI: $10.1007 / \mathrm{s} 11606-011-1691-\mathrm{Z}$

(C) Society of General Internal Medicine 2011 